\title{
Criatividade e imaginação: a pesquisa como transformação de mundo!
}

\author{
Celiane Camargo-Borges \\ Breda University of Applied Sciences \\ Tradução: Alexandre José Guimarães
} Instituto Federal de Educação, Ciência e Tecnologia de Goiás

\begin{abstract}
Resumo
$O$ artigo discute a criatividade e imaginação na pesquisa, questionando a visão dicotomizada: qualitativa versus quantitativa ou mesmo acadêmica versus aplicada. Oferece-se uma visão mais pragmática e orientada ao contexto, fundamentada em uma epistemologia de pesquisa como prática social. Essa aproximação epistemológica é apresentada através de projetos de pesquisa envolvendo métodos da arte para fomentar a criatividade e imaginação. Conclui-se que esta aproximação transforma a pesquisa do conceito de descoberta para 0 de generatividade, focando-se em questões como "para quem este conhecimento é útil?" Para além de comprovação de hipóteses o foco se dá na produção do conhecimento local. Por fim, o papel do pesquisador também se transforma de "poder sobre" para "poder com" pelo atributo da inclusão dos participantes no processo e no contexto da pesquisa. Publicação autorizada por Guilford Press, New York.
\end{abstract}

Palavras-chave: Psicologia. Imaginação na pesquisa. Métodos da arte.

É uma honra contribuir com este revolucionário livro sobre Pesquisa Baseada nas Artes (PBA), ${ }^{1}$ trazendo minha experiência em criatividade e imaginação na pesquisa e compartilhando como eu vejo e trabalho pesquisa como empreendimento criativo e imaginativo.

Desde o meu primeiro envolvimento com a pesquisa, eu sempre trabalhei com temas complexos, dinâmicos e imprevisíveis, como as interações e relacionamentos em organizações e comunidades, com ênfase especial em desenvolvimento e transformação.

\footnotetext{
${ }^{1}$ Nota do Editor. Este artigo foi publicado originalmente em inglês como "Creativity and Imagination: Research as World Making!", capítulo do livro Handbook of Arts-Based Research, organizado por Patricia Leavy, New York, Guilford Press, 2018. A versão em português é inédita e exclusiva. A autora e a revista ARJ - Art Research Journal agradecem aos editores a autorização para publicação de ambas as versões.
} 
Nesse contexto de investigação, eu tenho me debatido com o tradicional entendimento do que é fazer pesquisa, ou com o que Woolgar (1996) chama de "visão dominante da ciência" (VDC). A VDC é o que nós, classicamente, aprendemos sobre pesquisa, a qual é supostamente neutra, objetiva, replicável e assim por diante. Essa visão pressupõe que o mundo é formado por entidades independentes que podem ser descobertas, entendidas ou conhecidas através de práticas e sistemas "objetivos". De acordo com McNamee (2010), essas premissas levam, por sua vez, para relações casuais em pesquisa, como "se... então", abraçando uma visão linear da realidade, sem considerar história, cultura e contexto.

Trabalhar com pessoas e relações em certos contextos nos convida a um caminho/formato de investigação que se concentre nos saberes locais, na diversidade das vozes e nas dinâmicas de mudança. Portanto, a abordagem VRC de pesquisa e sua inclinação em direção à previsão começa a ser questionada. Perguntas emergem. Como posso escrever uma proposta de pesquisa sem conhecer o que minha comunidade quer/deseja? Como posso ser neutra se eu tenho algumas ideias e desejos para minha investigação? Como eu posso ser objetiva se todas as questões que eu formulo para minha pesquisa tem algumas suposições quem vem da minha visão de mundo, experiência e da teoria que eu adoto? Como minhas conclusões podem ser replicadas se cada grupo tem sua própria história e cultura?

Desde o início da minha carreira, que eu me foco numa questão: Como eu posso desenvolver um programa de pesquisa que seja orgânica, que envolva pessoas, comunidades, cidades e transformações sociais enquanto, ao mesmo tempo, possa receber reconhecimento acadêmico demonstrando seu rigor, sua qualidade e sua relevância?

As abordagens clássicas de pesquisa geralmente apresentam duas posições opostas: qualitativa versus quantitativa ou acadêmica versus pesquisa aplicada. Dentro desta distinção dicotomizada entre a abordagens, há uma quantidade esmagadora de literatura que dá base para essa separação dos métodos qualitativos dos quantitativos. Geralmente, as abordagens quantitativas são associadas às ciências duras, em que as medições, replicações, predições e controle são altamente valorizados e validados. Por outro lado, as abordagens qualitativas são identificadas pela literatura como ciência leve, pelo seu foco em aspectos subjetivos, produção de sentidos e palavras/linguagem ao invés de medidas e números. Entretanto, essa separação caricaturada mantém a visão dominante da ciência (VDC), em que a ciência dura (conhecimento universal) está separada das abordagens qualitativas (geralmente consideradas "leves").

Outra dicotomia comum é a distinção entre a pesquisa acadêmica e a pesquisa aplicada. Aqui, à pesquisa acadêmica é dado o mais alto status e ela está conectada ao "que realmente a ciência é", que inclui números, estudos randomizados e abordagens baseadas em evidências. A pesquisa aplicada, por outro lado, por ter o foco na prática, é vista como 
menos rigorosa, e portanto sendo colocada em um nível diferente porque, afinal, a pesquisa aplicada acaba sendo entendida como conduzida por profissionais, não por verdadeiros cientistas.

Você deve estar pensando agora que o mundo da pesquisa já se afastou de tais distinções dicotomizadas descritas anteriormente e que essa é uma crítica ultrapassada. Embora eu não concorde com essas oposições há pouco descritas, eu ainda experimento tal divisão em meu ambiente de trabalho, especialmente no cenário educacional/acadêmico, entre professores e alunos. Como acadêmicos, muitas vezes somos confrontados com financiamentos de pesquisa vindos de diversos lugares. Todos usam a linguagem do VRC, solicitando hipóteses, métodos e previsão de resultados a serem especificados antes mesmo que a pesquisa aconteça. Também tenho presenciado, em aulas de pesquisa, que os estudantes têm uma grande dificuldade em compreender outras visões de pesquisa e ciência para além da visão dominante da produção de conhecimento. Meus colegas e eu, trabalhando numa universidade de ciências aplicadas (há uma divisão na Holanda entre universidades profissionais e acadêmicas), frequentemente somos confrontados com questões se a pesquisa que nós ou nossos alunos estão desenvolvendo é acadêmica ou aplicada.

Envolvida já há algum tempo com essas questões e tendo me esforçado para encontrar uma linguagem que vá além dessas diferenciações, eu aprendi a palavra mágica que mudou toda a minha aproximação e entendimento da ciência, da produção de conhecimento, e de caminhos/formas para falar sobre pesquisa: epistemologia.

\section{Epistemologia: expandindo nossa compreensão do que é conhecimento}

"Epistemologia" pode ser descrita como o estudo do conhecimento, investigando questões como "Como nós sabemos o que sabemos"? Existem diferentes respostas para essa questão. Para alguns, o conhecimento é descoberto e, para outros, ele é construído. Thomas Kuhn (1970) foi o primeiro acadêmico a falar sobre paradigmas na ciência. Ele problematizou a noção científica do progresso em direção à verdade, afirmando que todas as nossas proposições sobre o mundo e conhecimento estão embasadas numa gama de suposições sobre o que existe e como o que existe funciona e pode ser acessado e como o trabalho científico deve prosseguir. Deste modo, a mais neutra e objetiva questão emerge de dentro de um paradigma, uma perspectiva específica sobre o mundo. De acordo com Kuhn, o conhecimento científico é um subproduto/um resultado de acordos negociados entre pessoas sobre a natureza do mundo.

Contudo, o paradigma clássico em ciência, a base racional para o conhecimento científico, afirma que a realidade de fatos e leis pode ser verificada através do uso de uma metodologia correta (SHAWVER, 2005). Central para este paradigma é a visão de que uma descrição empírica do mundo não possui bases ideológicas, sociais ou políticas. A 
epistemologia desta abordagem é empiricista - em que a produção de conhecimento está no processo de testar hipóteses sob a realidade (HERON; REASON, 1997). É sobre descobrir a realidade.

Esse paradigma clássico foi desafiado quando Kuhn (1970) introduziu a ideia de conhecimento como um subproduto de acordos negociados dentro da comunidade científica. Hoje, a epistemologia empiricista é vista como um possível entendimento negociado de conhecimento, não a compreensão do conhecimento (no sentido universal de conhecimento). Um paradigma relacional desafia a epistemologia empiricista - um paradigma relacional vê o conhecimento científico como um subproduto do processo histórico, social e cultural (SHAWVER, 2005). Com essa orientação em mãos, somos posicionados a considerar a ciência como uma prática social. Desse modo, ocorre uma transformação no conceito de produção de conhecimento e o que é tido como verdade, objetividade e validade. A abordagem epistemológica aqui é experimental, propositiva, cocriativa. Ao adotar essas distinções epistemológicas quando se fala sobre pesquisa, esclarece-se a abordagem adotada e justifica-se o desenho da pesquisa. Cada orientação epistemológica fornece critérios diferentes para validar e medir a pesquisa em termos de qualidade e validade.

Retornando ao paradigma relacional, nós precisamos perguntar: como essa abordagem epistemológica que é experimental, proposicional e co-criada surgiu e se desenvolveu na pesquisa?

Durante o século 20, um movimento científico crítico se desenvolveu. Esse movimento trouxe à superfície o comportamento da própria ciência. Este movimento crítico estava acontecendo num importantíssimo momento da história, o movimento da contracultura. Esse movimento questionou praticamente todas as nossas formas de entender a ordem social como algo dado. Tivemos o movimento feminista, o movimento negro e o movimento gay. $\mathrm{E}$ dentro das ciências sociais, nós tivemos o desenvolvimento da teoria crítica, da teoria feminista e da teoria pós-colonial, todas carregando uma abordagem muito revolucionária (GERDEN, 1994).

Este movimento trouxe um profundo deslocamento na concepção de conhecimento (trazendo o conceito de epistemologia para a superfície), o qual, até então, era visto como universal e inquestionável (especialmente na ciência). Esse movimento apontou para os aspectos ideológicos, sociais e políticos do discurso objetivo e neutro da ciência e da sociedade. Novas ideias e teorias relativas à produção de conhecimento emergiram desses movimentos, trazendo uma visão crítica de como o conhecimento é produzido e como a realidade é investigada.

Vale a pena mencionar a três principais críticas que realmente desempenharam o papel de questionar a neutralidade e universalidade do conhecimento/ciência: a ideológica, a retórica literária e a social (GERGEN, 1994). 
A crítica ideológica tenta revelar os valores que estão por trás das reinvindicações de verdade e razão, mostrando assim o processo pelo qual a ciência é ideologicamente construída. Os acadêmicos envolvidos nesta crítica expuseram as questões ideológicas, morais e políticas as quais, até aquele momento, eram apresentadas como um relato objetivo ou neutro da ciência e da sociedade. Hoje nós podemos reconhecer que todas as reinvindicações científicas são um projeto ideológico. O aspecto da ciência que é desafiado nesta crítica é a sua neutralidade e a produção da verdade. A crítica ideológica aponta para a existência de interesses pessoais/profissionais/corporativos, fins econômicos, valores morais e ideológicos por trás de uma afirmativa/afirmação alegadamente neutra.

As críticas retórico-literárias afirmam que a maneira pela qual estruturamos o conhecimento e, assim, a maneira que entendemos o mundo, é um subproduto do processo linguístico. Houve uma tentativa aqui de demonstrar que esses relatos, essas narrativas são determinadas não pelo caráter dos próprios eventos, mas por convenções literárias. Na medida em que os teóricos veem o mundo sob a perspectiva de suas próprias teorias, elas ficam limitadas ao que dizem e escrevem sobre o mundo. Observações e declarações do mundo são coerentes com um pano de fundo do conhecimento estabelecido. Portanto, não há conhecimento para além do literário. Ou, em outras palavras, descrições de mundo são limitadas pela linguagem disponível. Este tipo de crítica aponta para a importância da linguagem na criação da nossa realidade e não somente em sua representação. Não há conhecimento fora da linguagem.

O que está enfatizado na crítica anterior é que todas as buscas dos cientistas, tal como leis universais e gerais, descrevendo com precisão os assuntos e a reinvindicação correta sobre esses assuntos, estão todas embutidas na linguagem que, por sua vez, é uma criação coletiva relacionada a um lugar e a uma cultura (GERGEN; GERGEN, 2000).

Cientistas veem o mundo através das lentes de sua própria teoria e sua teoria tem regras indicando como descrever adequadamente este mundo - hipóteses, metodologia, análises, resultados e assim por diante. Desse modo, se você se envolve no processo de pesquisa de acordo com uma teoria específica, você alcança validade, ou, em outras palavras, a verdade. O centro desta questão é que ciência é retórica; é um discurso ou uma maneira de falar. Não é a verdade suprema. Cada discurso pertence a uma comunidade específica, que tem suas próprias regras e produz seus próprios saberes.

A terceira crítica revela a gênesis social do pensamento científico. Os autores apontam em direção ao contexto cultural em que várias ideias ganham corpo e os meios pelos quais essas ideias, por sua vez, dão forma às práticas científicas e culturais. Em outras palavras, cientistas criam "fatos". Estas três críticas fornecem o contexto para a emergência de um movimento em que uma nova onda de pesquisadores e novas teorias enfatizam a construção do conhecimento. O movimento tem muitos nomes, como pós-modernismo, pós- 
estruturalismo, modernidade líquida. O que esses pesquisadores têm em comum é a incredulidade em relação às meta-narrativas, em que a teoria é vista como uma representação da realidade. Quando a teoria é vista como uma meta-narrativa, a suposição é que a teoria pode ser traduzida como um mapa explicativo que deveria informar, prever e promover procedimentos padronizados sobre o que é o mundo. As teorias nas abordagens pósmodernas não são vistas como um mapa do mundo, mas como formas de ver e construir o mundo.

Este movimento chama atenção para a construção social do conhecimento, enfatizando que cada abordagem de conhecimento tem um contexto e seus próprios modelos, conceitos e questões. Isso é o que nós nos referimos como "foco nas questões epistemológicas". As teorias fornecem os parâmetros para como nós podemos conhecer o que nós conhecemos (mais uma vez, é sobre epistemologia).

Se adotarmos essa atitude radical em que a teoria é vista como um processo que constrói o mundo em que vivemos, então nós não precisamos ser fiéis e exclusivos de uma teoria. Nós podemos enriquecer a nossa pesquisa ao fazer uso das teorias como estruturas generativas e recursos para a mudança social. Podemos, então, adotar a criatividade e a abordagem imaginativa para pesquisar sem nos opormos à pesquisa tradicional, mas estando centrados/posicionados numa epistemologia diferente.

Uma abordagem criativa e imaginativa de pesquisa é fundamentada numa epistemologia que considera a pesquisa como uma prática social, uma ação coletiva de investigação (MCNAMEE; HOSKING, 2012). Isso é dramaticamente diferente do que ver a pesquisa como uma representação da realidade, a qual requer uma postura neutra, objetiva e controladora para alcançar a sua supremacia. Criatividade e imaginação na pesquisa é sobre evocar sentidos para construir um futuro melhor, ao invés designá-lo (GERGEN, 2015b).

\section{Criatividade no contexto da pesquisa}

A criatividade pode ser definida como um ato de reunir ideias e perspectivas que parecem paradoxais, no sentido de que elas mantêm características que normalmente não são mantidas juntas ou pelo menos não foram pensadas juntas (MONTUORI, 2006). Na investigação criativa, o pesquisador se afasta da lógica de uma única opção e navega em direção ao espectro de oportunidades, o tempo todo, sem pensar em termos de oposições ou polaridades, mas abraçando uma ambiguidade intuitiva e racional (MONTUORI, 2006).

Tradicionalmente, o conceito de criatividade esteve direcionado aos sujeitos e suas singularidades em ter ideias brilhantes. Esse entendimento está baseado na teoria do individuo-gênio, em que o seu talento é congênito e presente de Deus. Estudos mais recentes têm mostrado uma abordagem coletiva para a criatividade (CATMULL, 2008; MONTUORI, 
2011), em que as pessoas exercitam seu pensamento criativo juntas e criando, assim, ideias inovadoras. Isso também é chamado de "criatividade coletiva", que se refere às reflexões inovadoras que surgem da interação de ideias de diversas pessoas, em vez de uma única mente (MARION, 2011). A criatividade no contexto da pesquisa se refere à capacidade de ser curioso e ter uma mente aberta a fim de explorar e investigar para além do que está dado (os dados), com o objetivo de criar um futuro ainda inimaginável. É sobre uma estrutura de pesquisa como um processo criativo (MONTUORI, 2005), possibilitando criar o que "pode ser", em vez de firmar-se no "que é". O foco da criatividade em pesquisa é dar forma para ideias soltas, aparentemente não conectadas, organizá-las em possíveis conexões de melhor compreensão e, finalmente, criar novas ações.

Esta abordagem de pesquisa criativa desafia o conhecimento universal e sua inclinação para prever e controlar, e nos convida para um olhar atento ao conhecimento local, para diferentes vozes e perspectivas e para o dinamismo de nosso mundo/sociedade, em constante mudança. Se o conhecimento é co-criado pela relação, contexto e história, essa abordagem de pesquisa nos convida não apenas a um entendimento desta criação, mas também para a recriação de novas formas de conhecimento, com foco no que Gergen (2015b) chama de "pesquisa formadora de futuro", que se diferencia da pesquisa tradicional, em que a pesquisa é compreendida como espelho da realidade. Na pesquisa formadora de futuro, o objetivo não é olhar para o que "existe", mas criar novas formas de ação, construindo, assim, possíveis alternativas para a sociedade, organizações e comunidades. Para isso, criatividade e imaginação são fundamentais.

\section{Imaginação na pesquisa: possibilitando novos futuros}

Imaginar é a capacidade de ir além do estabelecido, da realidade apresentada, e experimentar novas combinações de sentido. Quando a imaginação é desencadeada, sentidos ganham liberdade e uma nova compreensão pode surgir. É por isso que a imaginação adota uma visão fluida e flexível de sentidos, incentivando a inventividade, a espontaneidade e a novidade. Através da imaginação, podemos criar novas imagens e cenários nunca antes pensados e, ao imaginar essas imagens e cenários, abrimos a possibilidade de trazê-los para a realidade. A imaginação também dá espaço à emergência de processos que são sementes de ideias que, quanto combinadas, podem trazer novas possibilidades. Estes processos geram novas formas e movimentos ao invés de focar apenas no que já existe. De acordo com Cooperrider e Whitney (2005), nossa imaginação coletiva pode legitimar potentes recursos e favorecer possibilidades de criação e mudança. Quando muitos participantes expõem suas visões e ideias sobre um tema, o potencial para criar experiências significativas é ampliado. 
Algumas abordagens de pesquisa já são orientadas para ativar a imaginação dos pesquisadores e participantes. As abordagens narrativas, por exemplo, apoiam-se em propriedades holísticas e heurísticas que provocam interpretação, variação, criatividade coletiva, produção de sentido e imaginação (GERGEN; GERGEN, 2010). Nijs (2015), ao descrever a metodologia do design chamada Imagineering ${ }^{2}$, uma forma de abordagem narrativa, distingue explicitamente o raciocínio científico lógico do raciocínio chamado por ela "modo narrativo". De acordo com a autora, o raciocínio científico busca uma aproximação "objetiva" para entender um fenômeno, enquanto o modo narrativo tenta compreender a partir da experiência e propósito humanos. As abordagens narrativas de pesquisa, que estão muito alinhadas com a abordagem imaginativa, não estão focadas em convencer pelo uso da verdade objetiva, mas através do uso da imaginação atrair e criar uma narrativa convincente que permita novas realidades. "O design de pesquisa no modo narrativo envolve as pessoas de maneira subjetiva, de forma criativa e orientadas para o futuro" (NIJS, 2015, p. 17).

A imaginação na pesquisa visa oferecer novas inteligibilidades e construir criativamente novas realidades. Quando adotamos a imaginação na pesquisa, nos movemos em direção à formação de novos futuros; portanto, nós queremos estimular as pessoas para imaginar suas necessidades e desejos. Nesse sentido, são necessárias outras formas de linguagem para explorar essa imaginação (WATKINS; MOHR; KELLY, 2011). Narrativas, poética social, imagens e vídeos podem ser usados para produzir novos conhecimentos e expressões.

\section{Uma orientação epistemológica para a pesquisa que adota a criatividade e a imaginação}

O Construcionismo Social é uma epistemologia que adota a imaginação e criatividade em pesquisa (CAMARGO-BORGES; RASERA, 2013). Essa aproximação teórica está fundamentada em um entendimento relacional e construído da produção de conhecimento (ANDERSON, 2014; GERGEN, 2015a; MCNAMEE; HOSKING, 2012), contendo quatro premissas principais.

O primeiro pressuposto é o caráter construído do mundo. Essa premissa desafia a ideia de uma "essência" de mundo que alguém possa capturar através da observação cuidadosa e de métodos empíricos. De acordo com a perspectiva construcionista, as categorias que usamos para denominar os processos são circunscritos pela cultura, história e pelo contexto social. A inteligibilidade de nossas percepções de mundo não deriva do próprio mundo, mas de nossa imersão na tradição das práticas culturais.

\footnotetext{
2 Imagineering tem sido traduzido no português como "engenharia da imaginação". Trata-se, também, de um mestrado oferecido pela Breda University of Applied Sciences.
} 
Ao dizer que o mundo é construído, temos a segunda premissa que aponta para a qualidade dessa construção. A realidade é produzida pelas trocas interativas entre pessoas em seus processos relacionais. Isso significa que qualquer que seja o relato que damos do mundo ou do eu, a sua origem está nas relações. Portanto, baseado nisso, a produção de conhecimento é sempre situada.

Assumir essas duas premissas - o mundo é construído e sua construção é efetuada nas interações sociais - nos leva para uma terceira. A validade e sustentabilidade do conhecimento não são mantidas ao longo do tempo por suas verdades empíricas, mas pelos processos sociais. Isso significa que o que consideramos ser verdade é um subproduto social, práticas interativas.

A quarta premissa é sobre a linguagem como ação. A linguagem, nessa abordagem, não é compreendida como descrição e representação de mundo, mas como um meio de construí-lo. Por isso linguagem e conhecimento não podem ser separados. A produção de conhecimento é uma forma de ação social. De acordo com os autores fundamentados nessa abordagem, a linguagem ganha sentido a partir de seu uso no contexto (BURR, 2003; GERGEN, 1994; MCNAMEE, 2004). A abordagem construcionista enfatiza a habilidade de criar realidades na linguagem.

Dadas essas premissas, a pesquisa/ciência é também um ato de construção ou reconstrução. Pesquisa é uma performance/atividade que empreendemos com discernimento. McNamee (2010) afirma que na abordagem construcionista social, "cada teoria, modelo e método é um discurso construído em comunidade" (p. 10).

Se nós adotamos essa abordagem epistemológica e a visão da ciência como uma prática social, estamos falando, então, sobre uma construção coletiva de uma determinada comunidade. Segundo Gergen (2014), a visão tradicional da ciência é aquela em que o conhecimento é uma compreensão cumulativa do mundo, produzindo hipóteses realistas sobre o mundo e a sociedade, que por sua vez são adotadas como "verdade". Se adotamos a abordagem epistemológica para a pesquisa como uma construção, então não precisamos nos restringirmos em posições tais como objetividade e neutralidade para o fenômeno de estudo, tentando descobrir o que ele é; em vez disso, podemos abrir nossa imaginação e usar nossa criatividade para focar no que ele pode ser. Gergen nos convida a reformular a investigação científica: de um espelho passivo que reflete o que é em um processo relacional ativo, moldando o que poderia ser (o futuro). Gergen desafia:

Se nos encontramos num mundo onde flutuações cada vez mais imprevisíveis marcam todas as facetas da vida - desde autoconcepção, vida familiar e comunidade até para configurações globais de poder, economia e doenças - qual é o lugar da pesquisa tradicional que tenta refletir um estado estável das coisas? Em que medida nós podemos sustentar um pressuposto de progresso em conhecimento? Como estou propondo, a visão mais promissora reside em uma ciência que se engaja na própria configuração das direções da mudança. (GERGEN, 2014, p. 11). 
O conceito de pesquisa como formação de futuros (GERGEN, 2015b) passa do espelhamento para a criação, iluminando o que pode ser criado ao invés do que já está "lá". É uma abordagem proativa de pesquisa, desenvolvida através de atividades coordenadas entre os envolvidos (pesquisadores e colaboradores). Juntos, através de processos imaginativos e criativos, os participantes criam alternativas que constroem um novo conhecimento que que faz sentido para o contexto específico e útil para os envolvidos.

\section{Desenho de pesquisa: formando futuros}

A abordagem construcionista em pesquisa é fundamental para investigar, entender e cultivar formas viáveis de convivência. É uma mudança radical da pura descoberta. As rápidas mudanças sociais e organizacionais do século XXI nos convidam para novas formas de pesquisa. Contudo, a fim de planejar e estruturar pesquisas orientadas relacionalmente - isto é, pesquisas que abordem ideias e conceitos construcionistas para a criatividade e imaginação -, novas abordagens e práticas inovadoras são urgentes.

Tradicionalmente, dados de pesquisa são entendidos apenas como algo que o pesquisador poderá coletar dos participantes, fazendo a pergunta certa sobre a natureza das coisas: a natureza do comportamento, do conhecimento e assim por diante. Isso pressupõe um mundo estável ao qual os participantes são solicitados a se remeter a eles. Esses tipos de questões presumem que algo que já existe está pronto para ser descoberto. Segundo Paré e Larner (2004), "a pesquisa não é um simples ato de encontrar algo, mas também é sempre um processo de criação coletiva" (p. 213). Uma abordagem criativa e imaginativa de pesquisa demanda uma orientação mais pragmática e reflexiva para as perguntas: O que queremos alcançar aqui? Quem está incluído? Quem está excluído? O que mais seria possível? Esses tipos de questões instigam nossa imaginação a vislumbrar o que ainda não existe e nos convida à criação de novas possibilidades.

Eu gostaria de oferecer uma maneira possível de construir uma pesquisa que abraçasse as ideias aqui apresentadas. Para trazer a criatividade e imaginação para a pesquisa, uma colega e eu desenvolvemos uma abordagem que chamamos de "designing research"3 (BODIFORD; CAMARGO-BORGES, 2014). Juntos investigamos meios práticos de desenvolver uma abordagem de pesquisa que poderia ser planejada a partir de sua demanda local. O termo designing vem do campo do design que, por sua natureza, tem uma abordagem centrada nas pessoas, bem como um conhecimento aplicável (ROMME, 2003; VAN AKEN, 2004). Designing também implica movimento, um convite a engajar/articular a pesquisa com

\footnotetext{
${ }^{3}$ Optei por não traduzir a expressão, sendo que não há uma tradução consensual para o termo inglês design. Na língua portuguesa, design está próximo de projeto, planejamento.
} 
a prática e a prática com a pesquisa (MOHRMAN, GIBSON; MOHRMAN, 2001; RYNES, BARTUNEK; DAFT, 2001).

Definimos quatro princípios para designing research (BODIFORD; CAMARGOBORGES, 2014), cuja base é construcionista. Com esses princípios, convidamos o leitor a perceber as visões de mundo tidas como dadas como algo socialmente construído, assim abrindo espaço para que construções alternativas sejam criadas, bem como novos meios de envolver sujeitos na pesquisa. O primeiro princípio aborda a pesquisa como relacional e colaborativa. A abordagem da designing research sustenta as relações como central na jornada colaborativa. O convite é para realizar pesquisa com e não para outras pessoas. Os participantes são convidados a trazer suas habilidades, saberes, interesses, experiências e histórias no coletivo para co-criar o processo de pesquisa. Na medida em que nos engajamos num processo relacional e colaborativo, há um movimento do pesquisador-como-especialista para o pesquisador-como-oferecedor-de-especialidades; um deslocamento de pesquisadorsujeitos para codesigners e coparticipantes da pesquisa.

O segundo princípio posiciona a pesquisa como útil e generativa, centrada na sua utilidade e pragmatismo. O foco é em como os pesquisadores se envolvem na investigação, objetivando gerar novas possibilidades e não presumindo a priori quais deveriam ser os temas e objetivos. Conforme os participantes vão fazendo parte do processo, novos entendimentos, significados e novas oportunidades são cocriadas. Finalmente, o processo criativo do método designing research produz significativas soluções em que consideramos cada sistema como único, aceitamos as experiências vividas, considerando e abraçando possibilidades futuras (BROWN, 2008; KIMBELL, 2011).

O terceiro princípio do método designing research aponta para o aspecto orgânico e dinâmico (ou emergente) da investigação. Este aspecto enfatiza o ato de condução da pesquisa como fluido, dinâmico e prática contínua, possibilitando um desdobramento à medida que os participantes se envolvem. Enquanto existe uma natureza emergente e orgânica para esse jeito de pensar a pesquisa, isso não quer dizer que não exista uma estrutura para apoiar e conduzir a investigação. Ter um propósito articulado, princípios e direção são importantes para manter as pessoas na investigação colaborativa. O designing research é dinâmico na medida em que as práticas participativas são cocriadas em todo o processo, envolvendo pesquisadores, participantes, teorias e métodos.

O quarto princípio do designing research foca no envolver-se em complexidade e multiplicidade. O designing research evita posições causais ou dualistas e se engaja em complexidade e multiplicidade como um rico e novo terreno para a ação em pesquisa. Abraçando a complexidade e multiplicidade com uma sensibilidade relacional expande nossa visão para envolver sistema como um todo. É sobre considerar e apreciar as muitas diferentes vozes envolvidas e convidar outras opiniões e pontos de vistas para multiplicar novas opções 
e aumentar a pluralidade na pesquisa. Podemos perguntar, "Quais novas ideias, conhecimento e entendimentos estão emergindo? O que estamos criando juntos?" Com essas perguntas começamos a ver as inter-relações e apreciar as interconexões que enriquecem as possibilidades.

O designing research como orientação foca na pesquisa desenvolvida através da emergência dos processos criativos e imaginativos que envolvem uma coletividade que constrói e reconstrói conhecimento e prática. Essa abordagem cria novas maneiras de envolvimento na pesquisa, abrindo espaço para projetos alternativos focados na localidade e na generalidade de conhecimento e práticas. Essa atitude para a pesquisa requer um processo dinâmico de interpretação que se sustente de forma aberta, flexível e enfática, em que o pesquisador se desloca dos "métodos de pesquisa" para as "práticas de investigação" (GERGEN, 2014, p. 51). Agora estamos prontos para perguntar sobre as possibilidades e oportunidades vindas dessa forma de investigação. Além disso, nossa preocupação se volta para as implicações em adotar essa abordagem de pesquisa. Uma ilustração do designing research será útil para traduzir as ideias discutidas na prática.

\section{Designing research na Uganda: uma ilustração}

Minha parceira de pesquisa, Kristin Bodiford, e eu, junto com uma ex-aluna do mestrado em Imagineering, Shirley Jane Timotheus, em parceria com duas organizações nãogovernamentais (ONGs) em Uganda (Hope for Youth Uganda, H4YU, e Health Nest Uganda, HENU), nos engajamos em uma investigação colaborativa. Essas ONGs trabalham com comunidades em Uganda, com foco no desenvolvimento local, saúde e educação. O objetivo dessa investigação era explorar possibilidades para estabelecer parcerias e saber mais sobre a comunidade local. Começamos com algumas reuniões por Skype para nos conhecer, saber dos nossos interesses e curiosidades e estabelecer um tema de pesquisa.

Nós não estávamos lá para descobrir ou avaliar nada sobre a cultura, organização ou a comunidade, mas para cocriar com eles. Nós entramos no campo como copesquisadores, o que significa que não estávamos lá como especialistas, mas como participantes com algumas especialidades, as quais tínhamos o desejo de relacioná-las com as especialidades de nossos parceiros em Uganda. Essa primeira fase do projeto focou no primeiro princípio de nos posicionar (como pesquisadores) de forma relacional e colaborativa, conhecendo o grupo, o contexto e compreendendo informações dentro do contexto local. Em equipe, começamos a projetar a pesquisa meses antes de entrar no campo. Entretanto, em vez de confiar apenas numa revisão da literatura e de outras fontes acadêmicas para definir "a lacuna" que precisava ser preenchida, mergulhamos em nossa criatividade e imaginação, prevendo juntos o que seria possível (envolver-se em complexidade e multiplicidade). Esse posicionamento nos ajudou também a ativar o segundo princípio: ser útil e generativo para o ambiente local. Essa 
primeira fase resultou numa proposta de pesquisa intitulada Discovering the Beauty of Uganda ${ }^{4}$, cujo objetivo foi a investigação da comunidade, analisando a produção de sentido das experiências e impressões sobre Uganda a partir do olhar dos jovens.

A abordagem de pesquisa que nós adotamos demandou outros métodos criativos e imaginativos, como os métodos baseados nas artes. Introduzimos aos participantes o método Photovoice (GRIEBLING; VAUGHN; HOWELL; RAMSTETTER; DOLE, 2013) ilustrando as necessidades e interesses dos participantes no contexto da pesquisa/intervenção. Esse método se baseia no poder e potencial da fotografia para possibilitar e encorajar os participantes a serem criativos e reflexivos. O método convida os participantes a imaginar possíveis alternativas futuras em um tema específico. Com o método Photovoice, nós oferecemos aos participantes um prazo para que tirassem fotos de coisas significantes para eles ou que tinham um significado histórico ou ainda que representassem uma experiência importante. Então estimulamos os participantes a trabalharem de forma colaborativa, convidando-os a usar a criatividade e a imaginação, ao escolherem livremente o que gostariam de compartilhar sobre si mesmos e seus arredores de maneira visual. Com suas câmeras, os participantes estão prontos para documentar e revelar o que eles apreciam sobre Uganda a o que eles gostariam de compartilhar. Fotografias e imagens cruzadas com encontros etnográficos são narrativas poderosas porque vão além da representação linguística racional, assim ampliando histórias e fornecendo uma visão complexa sobre um tema (LEAVY, 2015).

A fase de campo focou-se no terceiro princípio da pesquisa: orgânica e dinâmica. Enquanto que na perspectiva tradicional de coleta de dados existe uma suposição de que, com o método certo, a pesquisa "descobrirá" como as coisas "realmente são" a partir de um projeto orientado de pesquisa, nós podemos dizer nessa abordagem que, ao invés de coletar dados, estamos gerando (criando) dados, o que significa que é a interação entre participantesmétodo-equipe que promove a emergência de novas ideias e material com o qual trabalhar. O método baseado nas artes aqui aplicado convidou os participantes à interação e lhes permitiu explorar sua criatividade.

A coleta de dados se desenrolou à medida que os participantes se envolveram com o tema e o método cocriando sentidos junto à equipe visitante. Demos câmeras digitais a 20 jovens entre 8 e 26 anos. Eles percorreram a cidade de Entebbe e fizeram fotos daquilo que viam como a beleza de Uganda.

A próxima fase foi coletar todas as fotos produzidas. Os participantes se juntaram em pequenos grupos e começaram a contar as histórias de suas fotografias. As histórias se enriqueciam na medida que eram compartilhadas uns com os outros. Depois de escolher e

\footnotetext{
${ }^{4}$ Descobrindo a beleza de Uganda.
} 
imprimir algumas fotos, eles foram identificando e compartilhando sentidos assim como o que havia de especial em suas próprias experiências e histórias. O projeto de pesquisa terminou com uma exibição final num parque comunitário, promovendo o compartilhamento do resultado final com os membros da comunidade e seus líderes e mais uma vez ampliando a produção de sentidos no tema a partir das interações nesta exibição.

Storytelling 5 foi usado como método de pesquisa (Bochner e Riggs, 2014) para estruturar a análise dos dados (as fotografias selecionadas) e criar sentidos coletivos a partir do desenvolvimento de histórias contadas em grupo. Esse método de pesquisa é uma combinação de histórias e narrativas. Uma "narrativa" é construída a partir da combinação do que é comum em cada história individual, assim produzindo uma história cultural coletiva. É menos racional e mais simbólica e subjetiva. Uma história pode revelar múltiplas vozes, múltiplas construções e construir relações entre o sujeito e o tema. "Trabalhar com esse modelo pode abrir novas maneiras de se relacionar e criar novos mundos possíveis" (MCNAMEE; HOSKIN, 2012, p. 63).

É importante acrescentar que essa forma de pesquisa requer um comprometimento de abraçá-la como uma a prática relacional, engajada e dialógica. Isso significa que os processos criativos e imaginativos são necessários para garantir que a pesquisa faça sentido para todos os envolvidos.

A pesquisa em Uganda proporcionou uma oportunidade de criar "um epaço de investigação em quem diferentes visões puderam dialogar umas com as outras" (ALVESSON; DEETZ, 2000, apud MCNAMEE, 2010, p. 16-17). Quando se conduz dialogicamente uma pesquisa numa comunidade, a Designing Research abre novas possibilidades de parcerias e promove, também, novas histórias dentro da comunidade. Essa foi uma forma potente de cocriar novos diálogos e realidades e de encorajar os participantes a incorporar suas falas através da "construção e uso de artefatos em conjunto com outros corpos, conscientemente ou não" (MCNAMEE; HOSKING, 2012, p. 67). Compartilhar histórias, criar arte juntos e preparar uma exposição final legitimou possíveis caminhos em que as atividades não-verbais ampliaram o senso de entendimento e possibilidade dos participantes.

\section{Conclusão}

A pergunta que não quer calar: mas afinal ainda estamos falando sobre ciência? Meu entendimento, fundado na epistemologia da pesquisa do construcionismo social, é que pesquisa pertence à uma comunidade de prática e é sempre contingente e contextual. A partir desse entendimento, eu afirmaria que como estamos todos envolvidos com curiosidade,

\footnotetext{
5 Storytellling é um método possível de produção e análise de dados que vem das abordagens de pesquisa baseada nas artes.
} 
criatividade e imaginação, somos na verdade todos pesquisadores, na medida em que estamos sempre buscando sentido e entendimento, criando novos caminhos e práticas em nossas profissões e vidas. No contexto específico da academia, considerar esse tipo de processo como pesquisa, e como boa pesquisa, exige um esforço extra para encontrar uma linguagem comum. Este livro é um importante passo nessa direção. Ele nos ajuda a desenvolver uma linguagem alternativa para a ciência/pesquisa podendo criar uma forte narrativa, revelando diferentes formas de práticas. Meu desejo/esperança é que essas formas de práticas em pesquisa sejam adotadas e aceitas academicamente como pesquisa.

Quais são as implicações em assumir essa abordagem criativa e imaginativa na pesquisa? A primeira implicação está na parte do pesquisador. A pesquisa muda a sua compreensão de pesquisa da descoberta para a generatividade, concentrando-se nas perguntas: "Para quem essa informação/conhecimento é útil?" "Como esse conhecimento/informação poderá ajudar essa comunidade 'seguir em frente'?" (MCNAMEE, 2010, p. 17). Considerar essas questões tem implicações para a pesquisa, afastando-se das hipóteses, testes e validações do conhecimento para o foco na sabedoria local/conhecimento local, no que é necessário/desejado e no que é possível criar juntos.

Em relação aos métodos utilizados nessa ilustração, ao invés de adotar e trabalhar com parâmetros de um conjunto de "métodos, regras e procedimentos geralmente aceitos" (MCNAMEE, 2010, p. 10), os métodos foram escolhidos em relação ao contexto e as perguntas da pesquisa foram "com base numa ampla gama de questões, incluindo o que é pragmático, o que responde aos participantes da pesquisa, que formas de investigação podem ser compatíveis com os participantes e assim por diante" (MCNAMEE, 2010, p. 14). papel do pesquisador muda da posição de "poder sobre" implícita quando "aqueles com conhecimento (pesquisadores) são racionais e tem poder sobre os seus sujeitos (os pesquisados)" (McNamee, 2010, p. 11), para uma abordagem que convida a uma posição de “"poder com', estando aberto e considerando de quem são as vozes ouvidas, incluídas, excluídas e assim por diante" (MCNAMEE, 2010, p. 15).

\section{Referências}

ANDERSON, H. Collaborative dialogue based research as everyday practice: Questioning our myths. In: SIMON, G.; CHARD, A. (ed.). Systemic Inquiry: Innovation in Reflexive Practice Research. Farnhill, UK: Everything is Connected Press, 2014. p. 60-73.

BOCHNER, A; RIGGS, N. Practicing narrative inquiry. In: LEAVY, P. (ed.). Handbook of Qualitative Methods. New York: Oxford University Press, 2014. p.195-222.

BODIFORD, K; CAMARGO-BORGES, C. Bridging Research and Practice: Designing Research in Daily Practice. Al Practitioner, 2014.

BROWN, T. Design thinking. Harvard Business Review, 86(6), 84-92, 2008.

BURR, V. Social constructionism. London: Routledge, 2003. 
CAMARGO-BORGES, C.; RASERA, E. F. Social constructionism in the context of organization development: Dialogue, imagination, and co-creation as resources of change. Thousand Oaks, CA: Sage, 2013.

CATMULL, E. How Pixar fosters collective creativity. Cambridge, MA: Harvard Business School, 2008. COOPERRIDER, D.; WHITNEY, D. Appreciative Inquiry: A Positive Revolution in Change. San Francisco, CA: Berrett-Koehler Publishers, 2005.

GERGEN, K. J. (a). An invitation to social construction. Thousand Oaks: Sage. 3rd Edition, 2015.

GERGEN, K. J. Pursuing excellence in qualitative inquiry. Qualitative Psychology, 1(1), 49-60, 2014.

GERGEN, K. J. (b). From mirroring to world-making: Research as future forming. Journal for the Theory of Social Behavior, 45(3), 287-310, 2014.

GERGEN, K. J. (b). From mirroring to world-making: Research as future forming. Journal for the Theory of Social Behavior, 45(3), 287-310, 2015.

GERGEN, K.J.; GERGEN, M. Scanning the Landscape of Narrative Inquiry. Social and Personality Psychology Compass, 4/9: 728-735, 2010.

GERGEN, M.; GERGEN, K. Qualitative inquiry: Tensions and transformations. In: DENZIN, N.; LINCOLN, Y. (ed.). Handbook of Qualitative Research, 2nd Edition. 2000. p. 1025-1046.

GERON, J.; REASON, P. A participatory inquiry paradigm. Qualitative Inquiry, 3(3), 274-294, 1997.

GRIEBLING, S; VAUGHN, L.; HOWELL, B.; RAMSTETTERR, C.; DOLE, D. From Passive to Active Voice: Using Photography as a Catalyst for Social Action. International Journal of Humanities and Social Science, Vol. 3, No. 2, 2013. [Special Issue - January 2013]

KIMBELL, L. Rethinking design thinking: Part I. Design and Culture, 3(3), 285-306, 2011.

KUHNK, T.S. The structure of scientific revolutions. 2nd ed. Rev. Chicago: University of Chicago Press, 1970.

LEABY, P. Method meets art: Arts-based research practice. New York: Guilford Press, 2015.

MARION, R. Leadership of Creativity: Entity-Based, Relational, and Complexity Perspectives. In: MUMFORD, M. (ed.). Handbook of Organizational Creativity. Elsevier, 2011. p. 457-482.

McNAMEE, S. Research as Social Construction: Transformative Inquiry. Health and Social Change, Vol. 1, n. 1, p. 9-19, 2010.

McNAMEE, S. Social construction as practical theory: Lessons for practice and reflection in psychotherapy. In: PARÉ, D. A.; LARNER, G. (ed.). Collaborative practice in psychology and therapy. Binghamton, NY: Haworth Press, 2004. p. 9-39.

McNAMEE, S.; HOSKING, D.M. Inquiry as Engaged Unfolding. In: McNAMEE, S.; HOSKING, D.M. Research and Social Change: A Relational Constructionist Approach, New York: Routledge, 2012. p. 63-86.

MOHRMAN, S. A.; GIBSON, C. B.; MOHRMAN, A. M. Doing research that is useful to practice a model and empirical exploration. Academy of Management Journal, 44(2), 357-375, 2001.

MONTUORI, A. Beyond postmodern times: the future of creativity and the creativity of the future. Futures, Elsevier Publisher, 43, 221-227, 2011.

MONTUORI, A. Literature review as creative inquiry. Reframing scholarship as a creative process. Journal of Transformative Education. V.3, N.4, Oct. 2005.

MONTUORI, A. The quest for a new education: From oppositional identities to creative inquiry. ReVision, 28(3), 4-20, 2006.

NIJS, D. E. The complexity-inspired design approach of Imagineering. World Futures, 71(1-2), 8-25, 2015. 
PARÉ, D.; LARNER, G. (ed.). Collaborative practices in psychology and therapy. Binghamton, NY: Haworth Press, 2004.

ROMME, A. G. L. Making a difference: Organization as design. Organization Science, 14, 558-573, 2003.

RYNES, S. L.; BARTUNEK, J. M.; DAFT, R. L. Across the great divide: Knowledge creation and transfer between practitioners and academics. Academy of Management Journal, 44(2), 340-355, 2001.

SHAWVER, L. How the West became postmodern: A three part story. In: SHAWVER, L. Nostalgic postmodernism: Postmodern therapy. Oakland, CA: Paralogic Press, 2005. p. 34-67.

VAN AKEN, J. E. Management research based on the paradigm of the design sciences: The quest for field- tested and grounded technological rules. Journal of Management Studies, 41, 219-246, 2004.

WATKINS, J. M.; MOHR, B. J.; KELLY, R. Appreciative inquiry: Change at the speed of imagination (Vol. 35). Hoboken, NJ: Wiley, 2011.

WHITNEY, D.; COOPERRIDER, D.; GARRISON, M.; MOORE, J.; DINGA, L. Appreciative inquiry and culture change at GTE/Verizon. Appreciative Inquiry Commons, 1996. Retrieved from https://appreciativeinquiry.case.edu/intro/bestcasesDetail.cfm?coid=2880.

WHITNEY, D.; TROSTEN-BLOOM, A. The power of appreciative inquiry: A practical guide to positive change (2nd ed.). Brunswick, OH: Berrett- Koehler, 2010.

WOOLGAR, S. Psychology, qualitative methods and the ideas of science. In: RICHARDSON, J. T. E. (ed.). Handbook of qualitative research methods for psychology and the social sciences. Leicester, UK: BPS Books, 1996. p. 11-25. 